\title{
Qualitative and quantitative phytochemical evaluation of Quassia undulata (Guill. \& Perr.) D. Dietr. leaves using different solvent polarities
}

\author{
Ibraheem Oduola Lawal ${ }^{1, *}$, Adeniyi Olufunso ${ }^{1,2}$, and Ariwoola Oluwole ${ }^{3}$ \\ ${ }^{1}$ Biomedicinal Research Centre, Forestry Research Institute of Nigeria (FRIN), P.M.B 5054, Jericho Hills, Ibadan, Oyo State, Nigeria \\ ${ }^{2}$ Montane Forest Research Station, Forestry Research Institute of Nigeria, P.M.B 2019, Jos, Plateau State, Nigeria \\ ${ }^{3}$ Federal College of Forestry, Forestry Research Institute of Nigeria, P.M.B 5087, Jericho Hills, Ibadan, Oyo State, Nigeria \\ *Corresponding author: ibroodula@gmail.com
}

Published: December 25, 2021

Received: February 7, 2021

Accepted: July 2, 2021

Published on-line: September 5, 2021

\begin{abstract}
This study investigated solvent effects on the phytochemical composition of Quassia undulata leaves a medicinal plant used in treating arrays of diseases including fever and cough. The leaves were collected, washed, air-dried, pulverized and evaluated for some inherent phytochemicals using four different solvent systems based on their polarities. The solvents are methanol, acetone, ethyl acetate and chloroform. The methanol extract was found to have the highest number of secondary metabolites (saponins, tannins, flavonoids, steroids, coumarins, anthraquinones, alkaloids and phenols). None of the extracts tested positive for the presence of phlobatannins, terpenoids and emodins. The methanol extract was further analyzed quantitatively for some of the determined phytochemicals. Tannins had a concentration of $3.131 \mathrm{mg}$ of catechin equivalents per $100 \mathrm{mg}$ sample $(\mathrm{mg} \mathrm{CE} / 100 \mathrm{~g})$, alkaloids $-5.200 \%$, total phenolics - $11.828 \mathrm{mg}$ of gallic acid equivalents per gram of extract (mg GAE/g), flavonoids - 8.074 $\mathrm{mg}$ of quercetin equivalents per gram of extract $(\mathrm{mg} \mathrm{QE} / \mathrm{g})$ while $0.673 \%$ saponins were detected. The presence of these secondary metabolites might justify the ethnomedicinal uses of Quassia undulata leaves as their bioactivity has been found to be dependent on the solvent used for extraction.
\end{abstract}

Key words: Quassia undulata; secondary metabolite; medicinal plant; solvent system

http://dx.doi.org/10.5937/leksir2141012L

\section{INTRODUCTION}

Plants are known to produce a wide variety of chemical compounds which do not contribute to their growth and development directly. These chemicals are termed secondary metabolites (Asadi-Samani et al., 2016) or phytochemicals (Shakya, 2016) and have been channeled into curing a wide spectrum of diseases such as cancer, diabetes, neurological disorders, atherosclerosis, cardiovascular diseases and malaria to name a few (Asadi-Samani et al., 2016; Odubanjo et al., 2018a). The use of plants for medicinal and therapeutic purpose is referred to as herbal or phytomedicine and is presently practiced worldwide. WHO has recognized herbal medicine as an important component of primary health care (Shakya, 2016) and active ingredients of some drugs have been extracted from plants. Quassia undulata (Guill. \& Perr.) D.Dietr. commonly called Oriji by the Yoruba ethnic group of Nigeria and Akan-asante hotoro by Ghanaians is a perennial shrub or a small to fairly large tree of the family Simaroubaceae (Adeniyi and Lawal, 2020; Odubanjo et al., 2018a). It grows in grasslands of subtropical and tropical Africa, America, Australia and Asia (Iko and Eze, 2012). In Africa, the decoctions of its bark or root are used in treating fever, stomach complaints, cough, leprosy, insanity or dementia. A decoction of its leaves is used in treating ankylosis, rickets and varicose veins (Adeniyi and Lawal, 2020; Gyakari and Cobbinah, 2008; Odubanjo et al., 2018b). The fruit is used against head lice, and the seed is used in treating fever in Nigeria although it is considered poisonous in other places. Quassinoids isolated from the plant have been found to have antitumour and antimalarial activities (Ajaiyeoba et al., 1999). Extracts of its leaves and stems possess antibacterial and antifungal activities (Gyakari and Cobbinah, 2008). Ajayeoba et al. (1995) also reported the antimicrobial activity of crenatine (an alkaloid isolated from Q. undulata) against strains of Staphylococcus aureus and Bacillus cereus. The vast array of therapeutic or medicinal properties of medicinal plants can be linked to the presence of phytochemicals.

This study aimed to determine the effect of different solvents extraction on the phytochemical constituents of the leaves of Quassia undulata. A good solvent gives optimal extraction and conserves the chemical structure of desired compounds 
(Thouri et al., 2017). The type and polarity of different solvents usually determine the quantity, quality, toxicity, biological activities and biosafety of extracts (Wakeel et al., 2019). The solvents used in this study in the order of decreasing polarity are methanol $>$ acetone $>$ ethyl acetate $>$ chloroform.

\section{MATERIALS AND METHODS}

\subsection{Sample Collection}

Fresh leaves of Quassia undulata were collected from the herbal garden of Forestry Research Institute of Nigeria (FRIN), Ibadan, Oyo state, Nigeria. Plant identification and authentication was carried out at the Forest Herbarium Ibadan with voucher number FHI-102099.

\subsection{Preparation of extracts}

The leaves were washed by placing them under running water, they were air dried at room temperature for about two weeks; the dried samples were pulverized and stored in an air tight container prior to extraction. Amount of $20 \mathrm{~g}$ of the sample was soaked in $100 \mathrm{~mL}$ of each of the solvents in the ratio 1:5 (Fayinminnu et al., 2017). The mixture was stirred at intervals and filtered after 72 hours (Osibemhe and Onoagbe, 2015); the solvents were removed by means of a rotary evaporator at 40 ${ }^{\circ} \mathrm{C}$ under reduced pressure (Adeniyi, 2019). The concentrated extracts were stored in airtight bottles at $4{ }^{\circ} \mathrm{C}$ until they were screened.

\subsection{Qualitative phytochemical analysis}

This was carried out using the following standard procedures:

\subsubsection{Test for saponins}

Amount of $5 \mathrm{~mL}$ of each extract was added to $5 \mathrm{~mL}$ of distilled water and shaken vigorously. It was warmed in a water bath and the formation of a stable persistent froth indicates the presence of saponins (Rohit, 2015).

\subsubsection{Test for tannins}

This was carried out using Braymer's test. Amount of $2 \mathrm{~mL}$ of each extract was dissolved in $5 \mathrm{~mL}$ of distilled water, it was filtered and to the filtrate, $2-3$ drops of $5 \% \mathrm{FeCl}_{3}$ was added. The presence of green precipitate indicates the presence of tannins (Mir et al., 2016; Yadav et al., 2014).

\subsubsection{Test for flavonoids}

This was carried out using lead acetate test as described by Rohit (2015). Amount of $1 \mathrm{~mL}$ of each extract was added to $1 \mathrm{~mL}$ of $10 \%$ lead acetate solution. Formation of a yellow precipitate indicates the presence of flavonoids.

\subsubsection{Test for steroid}

Salkowski test was used to determine the presence of steroids. Amount of $2 \mathrm{~mL}$ of each extract was added to $2 \mathrm{~mL}$ of chloroform and $2 \mathrm{~mL}$ of conc. $\mathrm{H}_{2} \mathrm{SO}_{4}$. Production of a reddish brown ring at the junction shows the presence of steroids (Yadav et al., 2014).

\subsubsection{Test for phlobatannin}

Amount of $2 \mathrm{~mL}$ of $1 \% \mathrm{HCl}$ was mixed with $2 \mathrm{~mL}$ of each extract; it was boiled in a water bath for about 5 minutes. Presence of red precipitate shows positive result for presence of phlobatannins (Osibemhe and Onoagbe, 2015; Yadav et al., 2014).

\subsubsection{Test for terpenoids}

Amount of $2 \mathrm{~mL}$ of chloroform was added to $5 \mathrm{~mL}$ of each extract and $3 \mathrm{~mL}$ conc. $\mathrm{H}_{2} \mathrm{SO}_{4}$ was also added carefully. Reddish brown color at the interface shows the presence of terpenoids (Mir et al., 2016).

\subsubsection{Test for coumarins}

To $2 \mathrm{~mL}$ of each extract, $3 \mathrm{~mL}$ of $10 \% \mathrm{NaOH}$ was added. Yellow coloration indicates the presence of coumarins (Yadav et al., 2014).

\subsubsection{Test for emodins}

Amount of $2 \mathrm{~mL}$ of each extract was mixed with $2 \mathrm{~mL} \mathrm{NH}_{4} \mathrm{OH}$ and $3 \mathrm{~mL}$ benzene, red coloration shows the presence of emodins (Yadav et al., 2014).

\subsubsection{Test for anthraquinone}

Borntrager's test as described by Yadav et al. (2014) was used to check for the presence of anthraquinones. Amount of $3 \mathrm{~mL}$ of each extract was added to $3 \mathrm{~mL}$ of benzene and $5 \mathrm{~mL}$ of 10 $\%$ ammonia. A pink color in the ammonical layer indicates the presence of anthraquinones.

\subsubsection{Test for anthocyanins}

Amount of $2 \mathrm{~mL}$ of each extract was added to $2 \mathrm{~mL}$ of $2 \mathrm{~N} \mathrm{HCl}$ and ammonia. A pinkish red coloration shows the presence of anthocyanins (Yadav et al., 2014).

\subsubsection{Test for alkaloids}

Amount of $2 \mathrm{~mL}$ of each extract was added to few drops of Hager's reagent, a yellow precipitate shows positive result for presence of alkaloids (Yadav et al., 2014).

\subsubsection{Test for cardiac glycosides}

Legal's test was used to test for glycosides; $2 \mathrm{~mL}$ of extract was mixed with $3 \mathrm{~mL}$ chloroform and $10 \% \mathrm{NH}_{3}$ solution. Pink coloration shows a positive result (Osibemhe and Onoagbe, 2015).

\subsubsection{Test for phenols}

Amount of $2 \mathrm{~mL}$ of each extract was added to $2 \mathrm{~mL}$ of $5 \%$ aqueous ferric chloride. Appearance of blue color indicates the presence of phenols (Prabhavathi et al., 2016).

\subsection{Quantitative phytochemical screening}

Based on the result of the preliminary phytochemical analysis, the content of secondary metabolites (phenols, tannins, saponins, flavonoids and alkaloids) present in the methanol extract of $Q$. undulata leaves was determined.

\subsubsection{Determination of total phenolics}

The total phenolic content was determined using the method of Singleton et al. (1999) as described by Stanković (2011). Amount of $0.5 \mathrm{~mL}$ of methanolic solution of the extract was mixed with $2.5 \mathrm{~mL}$ of $10 \%$ Folin-Ciocalteu's reagent dissolved in water and $2.5 \mathrm{~mL}$ of $7.5 \% \mathrm{NaHCO}_{3}$. The blank was made up of $0.5 \mathrm{~mL}$ methanol, $2.5 \mathrm{~mL}$ of $10 \%$ Folin-Ciocalteu's reagent dissolved in water and $2.5 \mathrm{~mL}$ of $7.5 \% \mathrm{NaHCO}_{3}$. They were incubated at $45^{\circ} \mathrm{C}$ for 45 minutes and absorbance was read on a spectrophotometer at $765 \mathrm{~nm}$. A similar procedure was carried out for standard solutions of gallic acid and calibration curve was constructed. The concentration of phenolics was read from the calibration curve and total phenolics present in the extract were expressed in terms of $\mathrm{mg}$ of gallic acid equivalent per gram of extract (mg GAE/g) Stanković (2011)

\subsubsection{Determination of tannins}

The tannin content was determined according to the modified vanillin- $\mathrm{HCl}$ method described by Lawal et al. (2015) and Omoruyi et al. (2012). The vanillin- $\mathrm{HCl}$ reagent was prepared just before use by mixing equal volumes of $8 \% \mathrm{HCl}$ and $1 \%$ vanillin in methanol. Amount of $10 \mathrm{~mL}$ of $1 \%$ concentrated $\mathrm{HCl}$ in methanol was added to about $0.2 \mathrm{~g}$ of ground sample in a conical flask. The flask was stoppered and continuously shaken for 20 minutes; the content was further centrifuged at 
$2500 \mathrm{rpm}$ for $5 \mathrm{~min}$. About $1.0 \mathrm{~mL}$ of the supernatant was transferred into a test tube containing $5 \mathrm{~mL}$ of vanillin- $\mathrm{HCl}$ reagent. It was incubated at $30^{\circ} \mathrm{C}$ for 20 minutes and absorbance was read at $450 \mathrm{~nm}$. The tannin content was expressed as $\mathrm{mg}$ of catechin equivalents per $100 \mathrm{mg}$ of sample.

\subsubsection{Determination of saponins}

This was conducted using the method of Obadoni and Ochuko (2002) as described by Biradar and Rachetti (2013) with slight modifications. Amount of $50 \mathrm{~mL}$ of $20 \%$ aqueous methanol was added to $10 \mathrm{~g}$ of sample in a conical flask. This was placed on hot water bath (about $55^{\circ} \mathrm{C}$ ) for $4 \mathrm{~h}$ with continuous stirring. It was then filtered and the residue re-extracted using 100 $\mathrm{mL}$ of $20 \%$ aqueous methanol. The extracts were combined and reduced to $40 \mathrm{~mL}$ on water bath at $90{ }^{\circ} \mathrm{C}$. The concentrate was poured into a separating funnel and $10 \mathrm{~mL}$ diethyl ether was added to it and shaken vigorously. The ether layer was discarded while the aqueous layer was recovered and purification process was repeated. Amount of $30 \mathrm{~mL}$ of $n$-butanol was added and the $n$-butanol extracts were washed twice with 10 $\mathrm{mL}$ of $5 \%$ aqueous $\mathrm{NaCl}$. The remaining solution was heated to evaporation on water bath, the samples were then dried in the oven to a constant weight and saponin content was calculated as a percentage (Biradar and Rachetti, 2013).

\subsubsection{Determination of flavonoids}

This was measured using aluminium chloride colorimetric assay. Amount of $1 \mathrm{~mL}$ of extract and $4 \mathrm{~mL}$ of distilled water were added to a volumetric flask; $0.3 \mathrm{~mL}$ of $5 \% \mathrm{NaNO}_{2}$ was added and after 5 minute, $0.3 \mathrm{~mL}$ of $10 \% \mathrm{AlCl}_{3}$ was also added. Amount of $2 \mathrm{~mL}$ of $1 \mathrm{M} \mathrm{NaOH}$ was added after 5 minutes and the content of the flask was made up to the $10 \mathrm{~mL}$ mark with distilled water. Standard solutions of quercetin at 20,40, 60, 80 and $100 \mu \mathrm{g} / \mathrm{mL}$ were prepared in the same manner, absorbance for test and standard solutions were read against the blank at $510 \mathrm{~nm}$ on a spectrophotometer. Total flavonoid content was expressed as mg of quercetin equivalents per gram of extract (Mythili et al., 2014).

\subsubsection{Determination of alkaloids}

This was conducted using the method of Harborne (1984) as described by Biradar and Rachetti (2013) with slight modifications. To $5 \mathrm{~g}$ of sample in a $250 \mathrm{~mL}$ beaker, $200 \mathrm{~mL}$ of $10 \%$ acetic acid in methanol was added; it was covered and allowed to stand. After $4 \mathrm{~h}$, it was filtered and the filtrate was concentrated on a water bath to about one-quarter of its original volume. Conc. $\mathrm{NH}_{4} \mathrm{OH}$ was added to the extract dropwisely until precipitation stopped. The solution was allowed to settle, precipitate was collected and washed with dilute $\mathrm{NH}_{4} \mathrm{OH}$ and then filtered. The residue was dried and weighed as the percentage of alkaloids (Biradar and Rachetti, 2013).

\section{RESULTS}

\subsection{Qualitative analysis}

The result of the qualitative phytochemical constituent of the four different leaf extracts of Quassia undulata is presented in Table 1. It shows the presence of numerous secondary metabolites which are of great medicinal importance. Steroids, coumarins, anthraquinones, and alkaloids were present in all the four extracts, while phlobatannins, terpenoids and emodins were absent in all the extracts. The methanolic extract contained the highest number of phytochemicals, followed by the acetone extract, while the ethyl acetate and chloroform extracts had similar composition. Extraction of the phytochemicals with solvents of different polarity resulted in the identification of diverse chemical constituents in each of the extracts.

Generally, polar solvents provide optimum extraction of polyphenols when compared to non-polar solvents (Abbas et al., 2017; Abdel-Shafy and Mansour, 2017). This could be due to the interaction of the hydrogen bonds between their polar sites and those of the polyphenols (Thouri et al., 2017). This explains the extraction of these metabolites by the polar solvents (methanol and acetone) used in this study. Ethyl acetate, a semipolar solvent can dissolve sterols, alkaloids and glycosides (Widyawati et al., 2015).

Saponins which were detected only in the methanol extract have been found to have antidiabetic, antiatherosclerotic, antiHIV and gastroprotective effects. They also help in liver function and reduction of blood cholesterol (Chukwuebuka and Chinenye, 2015). Tannins, present in the methanol and acetone extracts inhibit HIV replication; have antibacterial and antiparasitic effects (Chukwuebuka and Chinenye, 2015; Lü et al., 2004). They have also been found to possess antioxidant and antiinflammatory effects (Osibemhe and Onoagbe, 2015). Flavonoids present only in the methanol extract have anticarcinogenic and antioxidant effects (Chukwuebuka and Chinenye, 2015; Yadav et al., 2014). Steroids which exhibit analgesic properties, and also influence activities of the central nervous system (Mir et al., 2016) were present in all the four extracts. Coumarins which have a wide array of medicinal properties ranging from antimicrobial, antidiabetic, antioxidant to antiinflammatory effects were found in all the extracts. They also have inhibitory action on enzymes and vitamin $\mathrm{K}$ (Poumale et al., 2013). Anthraquinones and alkaloids were present in all the extracts. The former have laxative effects which gives constipation relief (Bolen, 2020), while the latter protect against chronic diseases (Mir et al., 2016), malaria (Nafiu et al., 2013) and inflammation (Kumar et al., 2008). Anthocyanins are antioxidants that have been found to reduce the risk of heart disease and fight obesity (He and Giusti, 2010). Cardiac glycosides are used in treating congestive heart failure and cardiac arrhythmia. Phenols present in acetone and methanolic extracts have been found to have antioxidant, antiviral, hypotensive and antimicrobial properties (Chukwuebuka and Chinenye, 2015). Absence of phlobatannins, terpenoids and emodins in all the extracts suggests the absence of their therapeutic effects in the plant studied. Most of the phytochemicals detected have antinutritive properties such as enzyme inhibition, nausea, vomiting, diarrhea, paralysis, toxicity and death when taken in excess. Hence, they should be administered with caution and at reduced doses.

\subsection{Quantitative analysis}

The result of the quantitative analysis carried out on the methanol extract for the content of some secondary metabolites is shown in Table 2 below. The extract was found to contain total phenolics - $11.828 \mathrm{mg} \mathrm{GAE} / \mathrm{g}$, tannins - 3.131 $\mathrm{mg} \mathrm{CE} / 100 \mathrm{~g}$, flavonoids $-8.074 \mathrm{mg} \mathrm{QE} / \mathrm{g}$, saponins -0.673 $\%$ and alkaloids $-5.200 \%$.

The total phenolics content detected in this study $11.828 \pm 0.269 \mathrm{mg} \mathrm{GAE} / \mathrm{g}$ is slightly lower than $12.51 \pm 0.32 \mathrm{mg}$ GAE/g detected by Odubanjo et al. (2018b). They also detected a total flavonoid of $7.62 \pm 0.12 \mathrm{mg} \mathrm{QE} / \mathrm{g}$ in the aqueous leaf extract of Quassia undulata. Anusha and Sudha (2017) who analyzed the phytochemical profile and antimicrobial potential of methanol and aqueous extracts of bark and leaf of Quassia indica (Gaertn.) Nooteb reported that the methanol leaf extract of Quassia indica contained $1.08 \mathrm{mg} / \mathrm{g}$ flavonoid, $10.44 \mathrm{mg} / \mathrm{g}$ phenol, and $1.53 \mathrm{mg} / \mathrm{g}$ tannin. 


\begin{tabular}{|c|c|c|c|c|}
\hline \multirow[b]{2}{*}{ Phytochemicals } & \multicolumn{4}{|c|}{ Extraction solvent $^{\mathrm{a}}$} \\
\hline & Chloroform & Ethyl acetate & Methanol & Acetone \\
\hline Saponins (Froth's test) & - & - & + & - \\
\hline Tannins (Braymer's test) & - & - & + & + \\
\hline Flavonoids (Lead acetate test) & - & - & + & - \\
\hline Steroids (Salkowaski's test) & + & + & + & + \\
\hline Phlobatannins (Precipitate test) & - & - & - & - \\
\hline Terpenoids (Salkowaski's test) & - & - & - & - \\
\hline Coumarins (Reaction with $10 \% \mathrm{NaOH}$ ) & + & + & + & + \\
\hline Emodins (Reaction with ammonium hydroxide and benzene) & - & - & - & - \\
\hline Anthraquinones (Borntrager's test) & + & + & + & + \\
\hline Anthocyanins (Reaction with acid and ammonia) & + & + & - & - \\
\hline Alkaloids (Hager's test) & + & + & + & + \\
\hline CardiacGlycosides (Legal's test) & + & + & - & + \\
\hline Phenols (Ferric Chloride's test) & - & - & + & + \\
\hline
\end{tabular}

a Signs plus (+) and minus (-) denote presence or absence of phytochemicals, respectively.

Table 2. Concentration of some phytochemicals present in the methanolic leaf extract of Quassia undulata

\begin{tabular}{lr}
\hline Phytochemicals $^{\mathrm{a}}$ & Concentration $^{\mathrm{b}}$ \\
\hline Total phenolics [mg GAE/g] & $11.828 \pm 0.269$ \\
Tannins [mg CE/100g] & $3.131 \pm 0.000$ \\
Saponins [\%] & $0.673 \pm 0.003$ \\
Flavonoids [mg QE/g] & $8.074 \pm 0.016$ \\
Alkaloids [\%] & $5.200 \pm 0.000$ \\
\hline
\end{tabular}

a Abbreviations: $\mathrm{mg}$ GAE/g - mg of gallic acid equivalent per gram of extract; $\mathrm{mg} \mathrm{CE} / 100 \mathrm{~g}$ - $\mathrm{mg}$ of catechin equivalents per $100 \mathrm{mg}$ sample; $\mathrm{mg} \mathrm{QE} / \mathrm{g}$ - $\mathrm{mg}$ of quercetin equivalents per gram of extract

${ }^{\mathrm{b}}$ Data are presented as mean \pm standard deviation of three replicates

\section{CONCLUSION}

Generally, the present study shows a range of phytochemicals that can be obtained from different extracts of $Q$. undulata leaves; they can be explored for the treatment of various diseases. This supports the claim that the amount of secondary metabolites extracted from plants is dependent on the polarity of solvents used. Solvent effects revealed that methanol extracted the highest number of phytochemicals, while the non polar solvents (ethyl acetate and chloroform) extracted the least. As a result of this, methanol can be said to be the most effective solvent compared to acetone, ethyl acetate and chloroform. The medicinal properties of Quassia undulata leaf extracts may be due to the presence of the above mentioned metabolites. Further research on the potentials of Q. undulata leaves is continuous.

\section{FUNDING}

This research did not receive any specific grant from funding agencies in the public, commercial, or not-for-profit sectors.

\section{ACKNOWLEDGMENTS}

The authors remain grateful to Mr. Adegboyega of Pharmaceutical - Chemistry Laboratory, University of Ibadan for the assistance rendered in the laboratory; assistance of the staff of Biomedicinal Research Centre is also appreciated.

\section{REFERENCES}

Abbas, M., Saeed, F., Anjum, F. M., Afzaal, M., Tufail, T., Bashir, M. S., Ishtiaq, A., Hussain, S. and Suleria, H. A. R. (2017). Natural polyphenols: An overview, International Journal of Food Properties 20(8): 16891699.

Abdel-Shafy, H. and Mansour, M. (2017). Polyphenols: Properties, occurrence, content in food and potential effects, in R. G. Bhola (ed.), Environmental Science and Engineering (Multi-Volume Set), Studium Press LLC, Houston, TX, USA, pp. 232-261.

Adeniyi, O. and Lawal, I. (2020). Composition and evaluation of nutritional, anti-nutritional properties of Quassia undulata (Guill. \& Perr.) D Dietr leaves, Journal of Forestry Research and Management 17(1): 67-71.

Adeniyi, O. O. (2019). Extraction and characterization of underutilized seed oils sampled in South-Western Nigeria, International Annals of Science 7(1): 48-52.

Ajaiyeoba, E. O., Abalogu, U. I., Krebs, H. C. and Oduola, A. M. (1999). In vivo antimalarial activities of Quassia amara and Quassia undulata plant extracts in mice, Journal of Ethnopharmacology 67(3): 321-325.

Ajayeoba, E. O., Adeniyi, B. A. and Okogun, J. I. (1995). Antimicrobial activity of crenatine, an alkaloid synthesized from indole, Phytotherapy Research 9(1): 69-71.

Anusha, P. and Sudha, B. R. (2017). Phytochemical profile and antimicrobial potential of methanolic extracts of bark and leaf of Quassia indica (Gaertn.) Nooteb., The Journal of Phytopharmacology 6(5): 269-276.

Asadi-Samani, M., Kooti, W., Aslani, E. and Shirzad, H. (2016). A systematic review of Iran's medicinal plants with anticancer effects, Journal of Evidence-Based Complementary \& Alternative Medicine 21(2): 143153.

Biradar, S. R. and Rachetti, B. D. (2013). Extraction of some secondary metabolites \&thin layer chromatography from different parts of Centella asiatica L. (URB), American Journal of Life Sciences 1(6): 243-247.

Bolen, B. (2020). Anthraquinones benefits and side effects. Available at: www.verywellhealth.com/anthraquinones-1945348 (Accessed: 9/1/2021).

Chukwuebuka, E. and Chinenye, I. J. (2015). Biological functions and anti-nutritional effects of phytochemicals in living system, IOSR Journal of Pharmacy and Biological Sciences (IOSR-JPBS) 10(2): 10-19.

Fayinminnu, O., Adeniyi, O., Alabi, O. and Omobusuyi, D. (2017). Potentials of aqueous extract of pod husk Parkia biglobosa (Jacq.) Benth as a biopesticide in Okra (Abelmoschus esculentus (L.) Moench) production, Journal of Agriculture and Ecology Research International 12(1): 1-12.

Gyakari, J. and Cobbinah, J. (2008). Quassia undulata (Guill. \& Perr.) D.Dietr., [Internet] Record from PROTA4U. Louppe, D., Oteng-Amoako, 
A.A. \& Brink, M. (Editors). PROTA (Plant Resources of Tropical Africa / Ressources végétales de l'Afrique tropicale), Wageningen, Netherlands. <http://www.prota4u.org/search.asp>. Accessed $27 \mathrm{Au}$ gust 2021.

Harborne, J. B. (1984). Phenolic Compounds, in J. B. Harborne (ed.), Phytochemical methods: A guide to modern techniques of plant analysis, Springer Netherlands, Dordrecht, pp. 37-99.

He, J. and Giusti, M. M. (2010). Anthocyanins: natural colorants with health-promoting properties, Annual Review of Food Science and Technology 1: 163-187.

Iko, W. and Eze, S. O. O. (2012). Physicochemical characterization of Quassia undulata seed oil for biodiesel production, African Journal of Biotechnology 11(83): 14930-14933.

Kumar, A., Ilavarasan, R., Jayachandr, T., Decaraman, M., Aravindhan, P., Padmanabha, N. and Krishnan, M. (2008). Phytochemicals investigation on a tropical plant, Syzygium cumini from Kattuppalayam, Erode district, Tamil Nadu, South India, Pakistan Journal of Nutrition 8(1): 83-85.

Lü, L., Liu, S.-w., Jiang, S.-b. and Wu, S.-g. (2004). Tannin inhibits HIV-1 entry by targeting gp41, Acta Pharmacologica Sinica 25(2): 213-218.

Lawal, I., Grierson, D. and Afolayan, A. (2015). Phytochemical and antioxidant investigations of a Clausena anisata hook, a South African medicinal plant, African Journal of Traditional, Complementary and Alternative Medicines 12(1): 28-37.

Mir, M. A., Parihar, K., Tabasum, U. and Kumari, E. (2016). Estimation of alkaloid, saponin and flavonoid, content in various extracts of Crocus sativa, Journal of Medicinal Plants Studies 4(5): 171-174.

Mythili, K., Reddy, C. U., Chamundeeswari, D. and Manna, P. K. (2014) Determination of total phenol, alkaloid, flavonoid and tannin in different extracts of Calanthe triplicata., Research \& Reviews: Journal of Pharmacognosy and Phytochemistry 2(2): 40-44.

Nafiu, M. O., Abdulsalam, T. A. and Akanji, M. A. (2013). Phytochemical analysis and antimalarial activity aqueous extract of Lecaniodiscus cupanioides root, Journal of Tropical Medicine 2013: 1-4.

Obadoni, B. O. and Ochuko, P. O. (2002). Phytochemical studies and comparative efficacy of the crude extracts of some haemostatic plants in Edo and Delta states of Nigeria, Global Journal of Pure and Applied Sciences 8(2): 203-208.

Odubanjo, V. O., Ibukun, E. O., Oboh, G. and Adefegha, S. A. (2018a). Aqueous extracts of two tropical ethnobotanicals (Tetrapleura tetraptera and Quassia undulata) improved spatial and non-spatial working memories in scopolamine-induced amnesic rats: Influence of neuronal cholinergic and antioxidant systems, Biomedicine \& Pharmacotherapy 99: 198-204

Odubanjo, V. O., Oboh, G., Oyeleye, S. I. and Adefegha, S. A. (2018b). Anticholinesterase activity and phenolic profile of two medicinal plants ( Quassia undulata and Senecio abyssinicus ) used in managing cognitive dysfunction in Nigeria, Journal of Food Biochemistry 42(4): e12497.

Omoruyi, B. E., Bradley, G. and Afolayan, A. J. (2012). Antioxidant and phytochemical properties of Carpobrotus edulis (L.) bolus leaf used for the management of common infections in HIV/AIDS patients in Eastern Cape province, BMC Complementary and Alternative Medicine 12(1): 1186.

Osibemhe, M. and Onoagbe, I. (2015). Qualitative and quantitative phytochemical evaluations of Strophanthus hispidus stem bark, IOSR Journal of Pharmacy and Biological Sciences (IOSR-JPBS) 10(2): 120 124.

Poumale, H. M. P., Hamm, R., Zang, Y., Shiono, Y. and Kuete, V. (2013). Coumarins and related compounds from the medicinal plants of Africa, in V. Kuete (ed.), Medicinal Plant Research in Africa, Elsevier, Oxford, pp. 261-300.

Prabhavathi, R. M., Prasad, M. P. and Jayaramu, M. (2016). Studies on qualitative and quantitative phytochemical analysis of Cissus quadrangularis, Advances in Applied Science Research 7(4): 11-17.

Rohit, K. B. (2015). Preliminary test of phytochemical screening of crude ethanolic and aqueous extract of Moringa pterygosperma Gaertn, Journal of Pharmacognosy and Phytochemistry 4(1): 07-09.

Shakya, A. (2016). Medicinal plants: Future source of new drugs, International Journal of Herbal Medicine 4(4): 59-64.

Singleton, V. L., Orthofer, R. and Lamuela-Raventós, R. M. (1999). Analysis of total phenols and other oxidation substrates and antioxidants by means of Folin-Ciocâlteu reagent, Methods in Enzymology, Vol. 299 Elsevier, pp. 152-178.

Stanković, M. S. (2011). Total phenolic content, flavonoid concentration and antioxidant activity of Marrubium peregrinum L. extracts, Kraguje vac Journal of Science 33: 63-72.

Thouri, A., Chahdoura, H., El Arem, A., Omri Hichri, A., Ben Hassin, R. and Achour, L. (2017). Effect of solvents extraction on phytochemical components and biological activities of Tunisian date seeds (var. korkobbi and arechti), BMC Complementary and Alternative Medicine 17(248): 1-10.

Wakeel, A., Jan, S. A., Ullah, I., Shinwari, Z. K. and Xu, M. (2019). Solvent polarity mediates phytochemical yield and antioxidant capacity of Isatis tinctoria, PeerJ 7: e7857.

Widyawati, P. S., Budianta, T. D. W., Kusuma, F. A. and Wijaya, L. (2015). Difference of solvent polarity to phytochemical content and antioxidant activity of Pluchea indicia Less leaves extracts, International Journal of Pharmacognosy and Phytochemical Research 6(4): 850-855.

Yadav, M., Chatterji, S., Gupta, S. K. and Watal, G. (2014). Preliminary phytochemical screening of six medicinal plants used in traditional medicine, International Journal of Pharmacy and Pharmaceutical Sciences 6(5): 539-542. 